Functional

Ecology 1999

13, 711-724

\title{
Thermoregulatory abilities of Alaskan bees: effects of size, phylogeny and ecology
}

\author{
J. A. BISHOP* and W. S. ARMBRUSTER $\dagger$ \\ Institute of Arctic Biology and Department of Biology \& Wildlife, University of Alaska Fairbanks, Fairbanks, \\ Alaska 99775-7000, USA
}

\begin{abstract}
Summary
1. The thermoregulatory capabilities of 18 species of Alaskan bees spanning nearly two orders of magnitude of body mass were measured. Thoracic temperature, measured across the temperature range at which each species forages, was regressed against operative (environmental) temperature to determine bees' abilities to maintain relatively constant thoracic temperatures across a range of operative temperatures (thermoregulatory performance).

2. Previous studies on insect thermoregulation have compared thoracic temperature with ambient air temperature. Operative temperature, which integrates air temperature, solar radiation and effects of wind, was estimated by measuring the temperature of a fresh, dead bee in the field environment. It is suggested that this is a more accurate measure of the thermal environment experienced by the insect and also allows direct comparisons of insects under different microclimate conditions, such as in sun and shade.

3. Simple regression analysis of species and family means, and analysis of phylogenetically based independent contrasts showed thermoregulatory capability, ability to elevate thoracic temperature, and minimum thoracic temperature necessary for initiating flight all increased with body size.

4. Bumble-bees were better thermoregulators than solitary bees primarily as a consequence of their larger body size. However, their thermoregulatory abilities were slightly, but significantly, better than predicted from body size alone, suggesting an added role of pelage and/or physiology. Large solitary bees were better thermoregulators than small solitary bees apparently as a result of body-size differences, with small bees acting as thermal conformers.
\end{abstract}

Key-words: Apoidea, body size, operative temperature, thermoregulation

Functional Ecology (1999) 13, 711-724

\section{Introduction}

Insects of high latitudes and high elevations face thermal constraints during foraging in the summer as well as over-wintering (see Kingsolver 1983; Barnes et al. 1996). While insects with low levels of activity (e.g. walking and sitting still) or of very small body size and light wing loading can operate with relatively low thoracic temperatures $\left(T_{\mathrm{th}}\right)$, large flying insects must generally have higher $T_{\text {th }}$ (Heinrich 1974). Flying insects that can elevate $T_{\text {th }}$ can forage with some independence of environmental temperature (Heinrich \& Heinrich 1983a). In contrast, flying insects with $T_{\text {th }}$

*Present address: c/o Calderon, Apdo. 6-5356, El Dorado, Panamá, Republic of Panamá.

$\dagger$ Present address: Department of Botany, Norwegian University of Science and Technology, N-7034 Trondheim, Norway. conforming to environmental temperature are spatially and temporally restricted to habitats that are warm enough to allow adequate $T_{\text {th }}$ for flight.

Bee species richness varies widely among habitats in interior Alaska (Armbruster \& Guinn 1989). Warm, open, sunny habitats such as south-facing bluffs, river bars and roadsides have relatively rich solitary bee faunas compared with shaded forests and cool alpine habitats, even though the habitats are similarly rich in appropriate nectar-producing host plants (W. S. Armbruster \& J. A. Bishop, unpublished data). Bumble-bees (Bombus spp., Apidae), however, are almost equally diverse in all habitats of interior Alaska. It thus appears that bumble-bees (18 species in interior Alaska) inhabit sites of various thermal regimes while solitary bees (58 species in interior Alaska) are restricted to warm, open habitats. This suggests that there may be fundamental differences in 
712

J. A. Bishop \&

W. S. Armbruster

(C) 1999 British

Ecological Society,

Functional Ecology,

13, 711-724 the abilities of bumble-bees and solitary bees to regulate $T_{\text {th }}$ and forage at cool temperatures (see reviews in Heinrich 1979, 1993). Differences between thermoregulatory abilities of bumble-bees and solitary bees in subarctic Alaska (and elsewhere) may result from inherent differences in physiology, pelage, colour, size or some combination of these factors. (Differences in the nesting biology of solitary bees and bumble-bees could also contribute to this pattern, but are not analysed here.) The purpose of this study was to explore the role of size $v s$ other factors in determining these thermoregulatory differences.

The ability to elevate and regulate $T_{\text {th }}$ has been documented for bumble-bees (Heinrich 1972a, 1972b, 1975), honey-bees (Cooper, Schaffer \& Buchmann 1985; Dyer \& Seeley 1987) and a few large solitary bees (Chappell 1982, 1984; Nicolson \& Louw 1982; Heinrich \& Buchmann 1986; Baird 1986). Less is known about thermoregulation in smaller bees. Stone \& Willmer (1989b) have shown that elevation of $T_{\text {th }}$ over air temperature increases with size in bees once the effects of thermal regime and phylogeny have been removed. Very few studies, however, have reported on the abilities of solitary bees to regulate $T_{\text {th }}$ over a range of environmental temperatures (but see Stone 1993a,b), and none has employed integrated measures of the thermal environment ('operative temperature'; Bakken 1992;).

\section{OPERATIVE TEMPERATURE}

Ambient air temperature $\left(T_{\mathrm{a}}\right)$ is often an inaccurate measure of the thermal environment experienced by insects because the thermal environment is also influenced by radiation load and convective effects of wind (Chappell 1982a). $T_{\mathrm{a}}$, solar radiation and convective effects of wind can be integrated into a single measure by directly estimating the operative (environmental) temperature ( $T_{\mathrm{e}}$; Bakken 1976, 1980, 1992). The best measure of $T_{\mathrm{e}}$ is the temperature of a physical model that approximates the thermal properties and position of the study organism in the field environment. $T_{\mathrm{e}}$ for insects can be estimated by mounting a freshly killed insect on a thermocouple lead and placing it in the field environment (Parker 1982; Bakken 1992; Casey 1992; O'Neill \& Kemp 1992). A dead-insect thermometer cannot, of course, estimate the convective effects of flight and wing movement. Black-globe measurements have also been used to approximate environmental temperature of insect (e.g. Corbet et al. 1993) and this method can give quite similar estimates to dead-insect thermometers (W. S. Armbruster, R. Matsuki \& M. Lee, unpublished data). The advantages of dead-insect thermometers are that they equilibrate to the thermal environment more quickly and respond thermodynamically more like the living insect. Disadvantages relative to the black-globe thermometer include unwanted variance due to variation in arrangement of body parts (e.g. abdomen, legs, wings) and orientation of the insect relative to the sun. On balance, if care is used in deployment, the advantages of fresh insects as a $T_{\mathrm{e}}$ thermometer outweigh their disadvantages (Parker 1982; Bakken 1992; O’Neill \& Kemp 1992).

\section{THERMOREGULATORY CAPABILITIES OF INSECTS}

It is suggested that an insect's thermoregulatory capability comprises two major, interacting components: (1) the ability to maintain a relatively constant $T_{\text {th }}$ over a wide range of $T_{\mathrm{e}}$; and (2) the ability to elevate $T_{\text {th }}$ above $T_{\mathrm{e}}$ when $T_{\mathrm{e}}$ is relatively low. These are related to the slope and elevation, respectively, of the relationship between $T_{\text {th }}$ and $T_{\mathrm{e}}$. Both components may be influenced by body mass in insects (Bartholomew \& Heinrich 1973, 1978; Heinrich 1974, 1989; Bartholomew 1981; Casey \& Joos 1983; Heinrich \& Mommsen 1985; Stone \& Willmer 1989b; Stone 1993a,b). The magnitude of $T_{\text {th }}$ elevation over $T_{\mathrm{e}}$ in insects is determined by the input (metabolic heat) minus output (convective, evaporative and radiative heat loss) (Bartholomew 1981; Porter et al. 1994). Note that radiative heat gains to the insect, as well as the effects of $T_{\mathrm{a}}$ and convection, are included in its $T_{\mathrm{e}}$ (Bakken 1976, 1980, 1992). Metabolic rate and the rate of convective heat loss both increase (per unit mass) as the size of the insect decreases; however, the latter increases more rapidly with decrease in body size (May 1976; Bartholomew 1981; Porter et al. 1994). Because heat loss is proportional to surface area and metabolic heat production is proportional to thoracic volume, at small body sizes above a critical surface-area to volume ratio, convective heat loss becomes so great that production of metabolic heat is insufficient to elevate $T_{\text {th }}$ over $T_{\mathrm{e}}$. The influence of size on both components ( 1 and 2 above) of thermal performance was examined.

Small insects that occur in cool environments and are unable to elevate temperature before or during flight may evolve the capability of flying at lower $T_{\text {th }}$ than larger insects that can elevate $T_{\text {th }}$ (e.g. Heinrich $\&$ Mommsen 1985). Bumble-bees must have a $T_{\text {th }}$ of at least $29-30{ }^{\circ} \mathrm{C}$ to fly (Krogh \& Zeuthen 1941; Sotavalta 1954), but almost nothing is known about minimum $T_{\text {th }}$ of small solitary bees in flight. The first analysis of the relationship in bees between body size and minimum $T_{\text {th }}$ necessary for flight is presented here.

\section{Materials and methods}

\section{FIELD SITES}

Fieldwork was conducted in interior Alaska between May and July of 1990 and April and July of 1991. Interior Alaska has a continental climate with cold winters and warm summers. Bees start foraging in early to mid-April. Most species cease activity in late 
713

Thermoregulation of Alaskan bees

(C) 1999 British Ecological Society, Functional Ecology, 13, 711-724
July or early August (Armbruster \& Guinn 1989). The study sites in 1990 were Bonanza Creek Bluff, 25 km south-west of Fairbanks, Alaska $\left(64^{\circ} 42^{\prime} \mathrm{N}, 148^{\circ} 18^{\prime} \mathrm{W}\right)$ and Moose Creek Bluff, $35 \mathrm{~km}$ south-east of Fairbanks, Alaska $\left(64^{\circ} 44^{\prime} \mathrm{N}, 147^{\circ} 14^{\prime} \mathrm{W}\right)$. The study site at Bonanza Creek Bluff was a patch of roadside vegetation dominated by two legumes, Hedysarum boreale and Hedysarum alpinum (Fabaceae), at the base of the south-facing bluff. The bee fauna and pollination interactions of the site have been described by Armbruster \& Guinn (1989), Armbruster \& McGuire (1991) and McGuire (1993). The Moose Creek Bluff study site was a south-facing river bluff with predominantly azonal subarctic steppe vegetation (described by McGuire \& Armbruster 1991). Fieldwork in 1991 was done at Kathul Mountain near the confluence of Washington Creek and the Yukon River, $\approx 80 \mathrm{~km}$ north-west of Eagle, Alaska $\left(65^{\circ} 22^{\prime} \mathrm{N}, 142^{\circ} 16^{\prime} \mathrm{W}\right)$. Habitats in which bees were caught included riverbanks, steppe on south-facing slopes, and alpine tundra (see Edwards \& Armbruster 1989; Lloyd, Armbruster \& Edwards 1994). Additional information on the taxonomy of bees in interior Alaska (including authors of species) can be found in Armbruster \& Guinn (1989).

\section{PASSIVE COOLING RATES}

Cooling curves for females or workers of 10 species, and both males and females of one species were measured to determine the relative importance of convective heat loss. Freshly killed bees were mounted on a 29 gauge thermocouple probe (Physitemp MT-29/2; Physitemp Instruments Inc., Clifon, NJ) ventrally inserted to the middle of the thorax, and placed next to a gasoline lantern (Coleman 285-700; Coleman Camping Equipment Inc., Wichita, KS), which served as a radiant head source. When the temperature of the thorax of the mounted bee $\left(T_{\text {th }}\right)$ reached $22{ }^{\circ} \mathrm{C}$ above $T_{\mathrm{a}}$, the lantern was removed, and $T_{\text {th }}$ was recorded every $5 \mathrm{~s}$ until the bee temperature reached ambient air temperature (generally $\approx 10{ }^{\circ} \mathrm{C}$ or less). Completely eliminating air currents was impossible because all measurements were done in a tent at the field site. However, if a draught was felt during a recording session, the measurement was not included. Each recording session lasted a maximum of $5 \mathrm{~min}$, and $T_{\mathrm{a}}$ never changed more than $1{ }^{\circ} \mathrm{C}$ in the tent during a run. Cooling rates were measured for three individuals of each 'size group' (caste or sex partitioned by species, e.g. female Anthophora bomboides, vs male A. bomboides, vs female Osmia bucephala, vs queen Bombus sylvicola).

Cooling curves were log-transformed to obtain a linear relationship. The slope of the log-linearized relationship is the cooling constant, a measure of the passive cooling rate (cf. Wathen, Mitchell \& Porter 1971). These thoracic cooling rates are probably very close, but not identical, to those experienced by live bees that warm endothermally, because the heads and abdomens were also heated by the experimental warming process (whereas only the thorax is warmed endothermally). However, cooling rates should approximate the cooling rates of more ectothermal bees whose heads and abdomens warm along with thoraces during basking. The mean cooling constants were regressed against $\ln$ (mean dry mass).

\section{MEASUREMENT OF THORACIC TEMPERATURE}

During the course of the bees' flight seasons, field sites were visited each day before bees started foraging, and $T_{\text {th }}$ was measured during most of the diel period of bee activity. In this way it was possible to obtain, for each common species, accurate estimates of minimum $T_{\mathrm{e}}$ of flight and a full range of $T_{\mathrm{th}}$ under a range of thermal environments. Uncommon species were therefore not included in the analyses.

Most studies of thermoregulatory capability of insects have measured $T_{\text {th }}$ of insects in flight (Heinrich 1975; Chappell 1982, 1984; Heinrich \& Buchmann 1986). In this study, however, $T_{\text {th }}$ at which a bee can take off was measured. This was chosen for two reasons: (1) $T_{\text {th }}$ at takeoff is more easily measured in a consistent way (just as the insect takes off) and likely to be less variable than $T_{\text {th }}$ during flight (the latter is affected by flight speed and prior activity levels); and (2) achieving minimum $T_{\text {th }}$ necessary for flight at takeoff is probably a critical challenge to foraging in cool weather. Although bees can sometimes take off but not maintain flight (G. Stone, personal communication), this was not observed at our study sites (or if it did occur, it resulted in bees moving between flowers in a normal foraging pattern). Because bees were not disturbed prior to takeoff, we believe they generally initiated flight under conditions that allowed them to maintain flight for ecologically meaningful periods of time. Bees often allow $T_{\mathrm{th}}$ to drop while feeding on flowers and warm up just prior to flight (Heinrich \& Heinrich 1983b; Waddington 1990). Thus, it was not assumed that a bee on a flower could fly, and bees were captured only after a successful foraging visit and voluntary takeoff.

Thoracic temperatures of live bees were measured in 21 'size groups' (as defined above: caste or sex partitioned by species), representing 18 species of solitary and social bees in interior Alaska. Different castes (queens and workers) of bumble-bees of the same species were treated separately because of the differences in body mass. Male and female solitary bees were also treated separately because of differences in size and potentially in thermoregulatory ability. Bees were sampled over the entire range of environmental temperatures at which they were found foraging on flowers.

$T_{\text {th }}$ was measured under field conditions for each bee captured in the field. Bees were captured with an insect net immediately upon takeoff from flowers and immobilized against a gloved finger. A 29-gauge thermocouple probe (Physitemp MT-29/2; time constant = 
$0.025 \mathrm{~s}$ ) was immediately inserted into the middle of the thorax and the temperature was read to the nearest $0 \cdot 1{ }^{\circ} \mathrm{C}$ on a digital thermometer (Omega Model $\mathrm{HH}$ 72T; Omega Engineering Inc., Stamford, CT). To minimize the potential for inaccurate readings because of convective cooling or to heat production from the flight muscles caused by agitation, the bee was not used if $T_{\text {th }}$ could not be measured within $7 \mathrm{~s}$ of capture (see Stone $\&$ Willmer 1989a). The temperature of the flight muscle of honey-bees has been shown to be fairly constant throughout the muscle (Feller \& Nachtigall 1989), and the gradient from the core to the surface is expected, on theoretical grounds, to be very small in small insects (W. P. Porter, personal communication). Therefore, inadvertent variation in placement of the probe within the flight muscle was probably not a source of much error. Each specimen was retained for later identification.

One concern was that the thermal mass of the probe would influence the $T_{\text {th }}$ reading from smaller bees. To assess the severity of this problem, dead Evylaeus comagenensis (Halictidae), one of the smallest bees (fresh mass $\approx 10 \mathrm{mg}$ ), were placed in a $5^{\circ} \mathrm{C}$ walk-in refrigerator and allowed to equilibrate to $T_{\mathrm{a}}$. To determine the effect of probe temperature on $T_{\text {th }}$, a probe that had been in a warm water bath was inserted into the bee's thorax. When the probe was $30^{\circ} \mathrm{C}$ warmer than the dead bee, $T_{\text {th }}$ read only $0.5^{\circ} \mathrm{C}$ warmer than actual $T_{\mathrm{th}}$. Because $T_{\mathrm{th}}$ was altered so little by a beeprobe temperature differential that was greater than that experienced in the field, we considered the effect of probe temperature on $T_{\mathrm{th}}$ of small bees to be negligible (see also Stone \& Willmer 1989a).

$T_{\mathrm{e}}$ was measured at the time of each capture by measuring $T_{\text {th }}$ of a recently killed bee mounted on a thermocouple (which Bakken 1992 has termed a $T_{\mathrm{e}}$ thermometer). The bee used as a thermometer was the same size group (species/caste/sex) as the live bee under study and was positioned in as a natural a posture as possible (e.g. wings partially spread), oriented horizontally and placed next to the flower on which the bee was foraging.

To determine whether the time since collection of the bee used for the $T_{\mathrm{e}}$ thermometer introduced variance in the $T_{\mathrm{e}}$ reading, $T_{\mathrm{e}}$ measured with five freshly killed honey-bees was compared with $T_{\mathrm{e}}$ measured with five honey-bees killed 3 days previously. The $T_{\mathrm{e}}$ readings were identical (to the nearest $0 \cdot 1{ }^{\circ} \mathrm{C}$ ) across all bees, and therefore small differences in age of $T_{\mathrm{e}}$ carcasses were not considered to be a source of significant error.

\section{SIZE VARIABLES}

Body dry mass was measured from specimens mounted on preweighed pins. The bees were dried for two months under ambient laboratory conditions $\left(T_{\mathrm{a}}\right.$ $\approx 23{ }^{\circ} \mathrm{C}$, relative humidity $\approx 15 \%$ ). The remote field location precluded measurement of fresh mass. The dry mass/fresh mass ratio was calculated for a total of
22 individuals from six species in the Anthophoridae and Apidae to allow estimation of fresh mass. Average dry mass was $36.8 \%$ (standard deviation $=4.7 \%$ ) of fresh mass.

Thoracic volume was calculated using the equation for an ellipsoid:

$V=4 / 3 \Pi a b c$ eqn 1

where $a=$ length $/ 2, b=$ width $/ 2$ and $c=\operatorname{depth} / 2$. Thoracic volume values are means of four randomly selected specimens of each size group.

Wing loading was calculated by dividing dry mass by wing surface area. Wing surface area was measured with a video digitizer interfaced with a desktop computer.

Only mean values of size variables were used in further statistical analyses. Means differed significantly among all size groups. The standard deviations were small relative to the means and are therefore not reported in Table 1.

\section{THERMOREGULATORY PERFORMANCE}

The thermoregulatory performance index was defined as the slope of the relationship between $T_{\mathrm{th}}$ and $T_{\mathrm{e}}$ and was calculated for each species using ordinary leastsquares regression on individuals within a size group (species and caste/sex). A slope of 0 indicates that $T_{\text {th }}$ is independent of $T_{\mathrm{e}}$ and a slope of 1 indicates thermal conformance. The relationship between $T_{\mathrm{th}}$ and $T_{\mathrm{e}}$ was not significantly different from linear across the observed $T_{\mathrm{e}}$ range for all size groups investigated in this study, allowing use of simple linear regression. Although least-squares regression assumes no error in the $x$-values (and there was sampling as well as measurement error in our size measurements), it is in wide use for studies such as these (Neter, Wasserman \& Kutner 1985). There are two reasons for this. Alternatives, such as Type-II (major axis) regression, have not been developed as thoroughly, have their own statistical problems, and tend not to deviate very much from least squares when the relationship is reasonably strong (Neter et al. 1985; Pagel \& Harvey 1988). If least-squares regression introduced a bias, it would probably have accentuated slightly the differences between thermoregulators and conformers, by underestimating the slope for the former but not for the latter (see Pagel \& Harvey 1988). We think this problem is minor, but it should be borne in mind.

THORACIC TEMPERATURE ELEVATION AND MINIMUM TEMPERATURE FOR TAKEOFF

The $T_{\text {th }}$ elevation index is a measure of the ability of each species to elevate $T_{\mathrm{th}}$ above $T_{\mathrm{e}}$ and was defined as the difference between $T_{\mathrm{e}}$ and the expected value of $T_{\mathrm{th}}$ (calculated from the $T_{\mathrm{th}} / T_{\mathrm{e}}$ regression equation) at the lowest air temperature at which bees were observed foraging. Although functionally similar to the $y$-inter- 
715

Thermoregulation of Alaskan bees cept, this value was used instead because it was considered biologically more relevant. This index is preferable to the average $T_{\mathrm{th}}-T_{\mathrm{e}}$ value for all bees measured because the maximum attainable difference at low temperatures is an indication of the thermal constraints placed on behaviour. The minimum $T_{\text {th }}$ at which bees were observed to be able to take off was assessed from the range of measured $T_{\mathrm{th}}$ for each size group.

\section{STATISTICAL ANALYSES}

Thermoregulatory performance index, elevation of thoracic temperature and minimum thoracic temperature at takeoff were regressed 'naïvely' (see Grafen 1989) against the natural log of mean dry mass, thoracic volume and wing loading for all bee size groups (as defined above). The size measures were too highly intercorrelated to use in multiple regression. Body dry mass appeared to be the best general measure of size and is most widely used; it alone was used in the more detailed analyses. In all the analyses, mass was natural log-transformed to linearize relationships with the $y$ variables.

Most size groups comprised female bees. However, measurements were also made on male and worker bees and treated as different size groups. These additional size groups were included in our analyses to increase the sample size and size range. Although there is a risk of obscuring or creating patterns by pooling heterogeneous data, inspection of the data and residuals suggested that including females, males and workers in the same analysis would not cause statistical problems. To test this assumption, all analyses were repeated without males and workers. The results were very similar; the correlation coefficients changed by less than $10 \%$ in all cases, and therefore only the results of analyses of the full data set are reported.

The statistical estimates of relationships based on data pooled from species belonging to several higher taxa (or clades) represent a blend of within- and among-group (clade or taxon) relationships (Armbruster 1988, 1992, 1996; Bell 1989; Harvey \& Pagel 1991). Furthermore, species are not independent observations but rather structured by phylogeny; hence the phylogeny of species being compared should be incorporated in the analysis of comparative data (Felsenstein 1985; Harvey \& Pagel 1991; Armbruster 1992). Two additional analyses were conducted to deal with these problems. To assess the seriousness of the first problem, the among-species relationships were compared with the among-family relationships between thermoregulatory parameters and mean dry mass. Generic means were used in calculating family means to prevent genera with several sampled species from biasing family means.

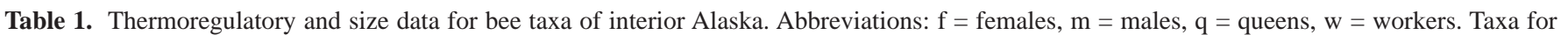
which cooling constants were calculated are denoted with an asterisk. 95\% confidence intervals of the thermoregulatory performance index are shown in parentheses

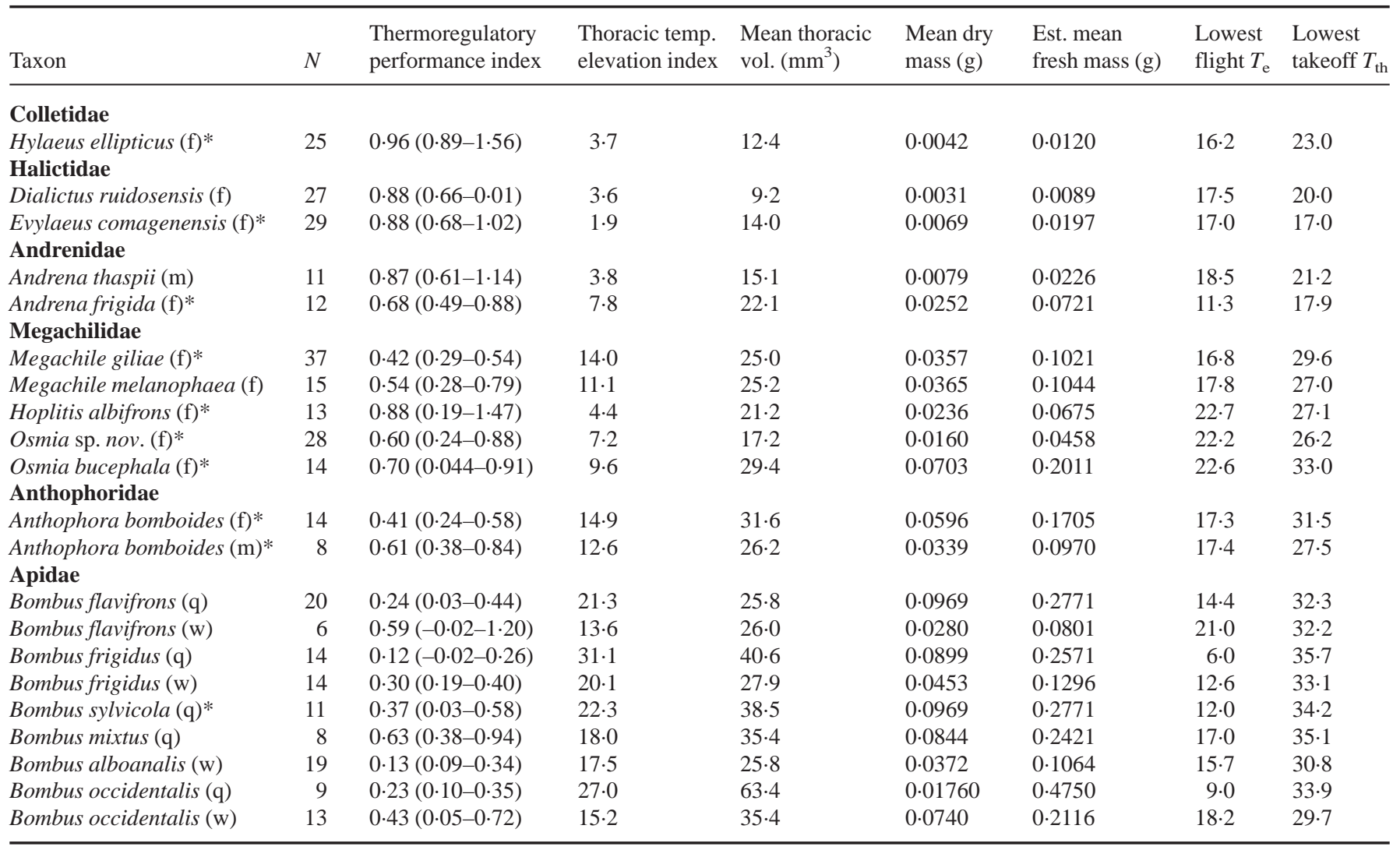


716

J. A. Bishop \&

W. S. Armbruster
To deal with the problem of phylogenetic structure in the data, Pagel's (1992) modification of Felsenstein's (1985) method of analysing independent contrasts, as operationalized by Purvis \& Rambaut (1995) in their computer program CAIC, was employed. Phylogenetic relationships were inferred from taxonomic information presented in Michener,

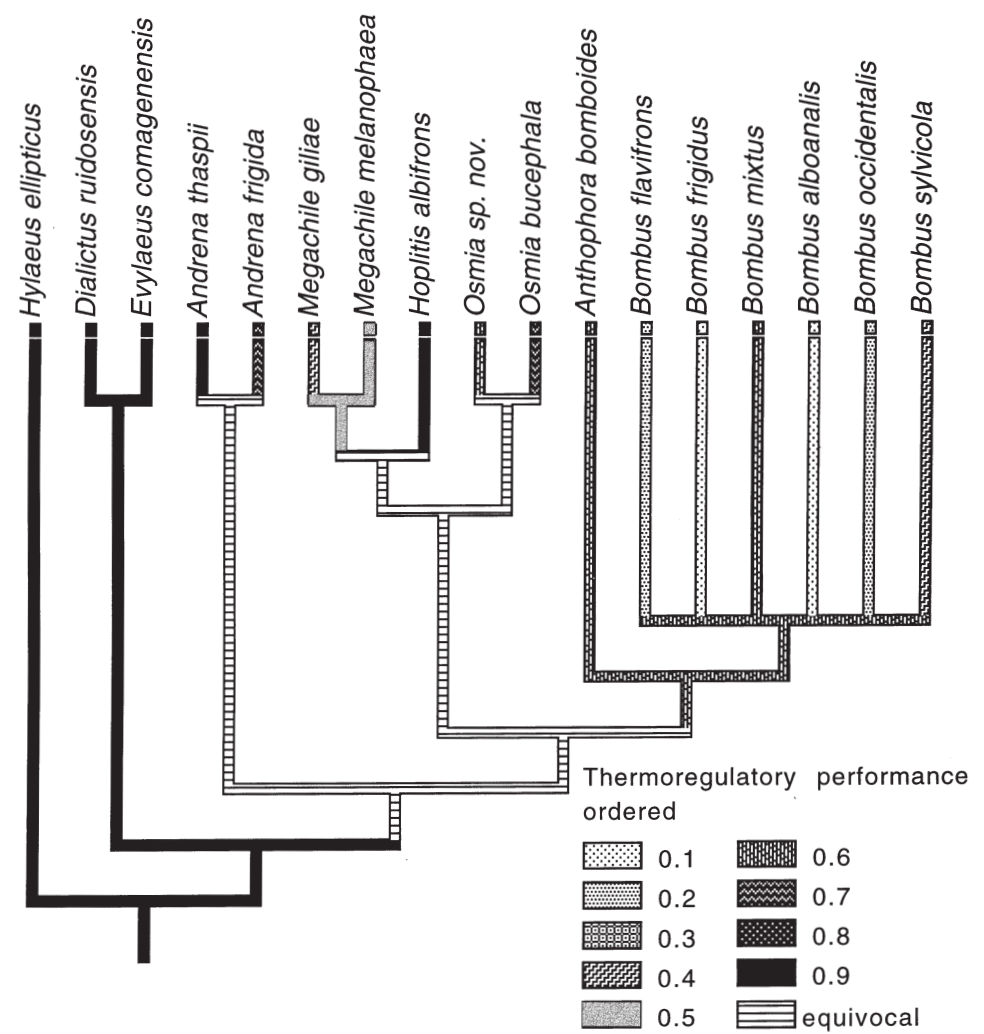

Fig. 1. Inferred phylogeny of bee genera used in independent-contrasts analysis, based on taxonomic information presented in Michener et al. (1994) and the phylogeny presented in Michener (1974), as modified for Anthophoridae/Apidae by Roig-Aisina \& Michener (1993). The thermoregulatory performance index was mapped onto the phylogeny using ordered-state parsimony (Maddison \& Maddison 1992) to illustrate the apparent evolutionary lability of this trait.

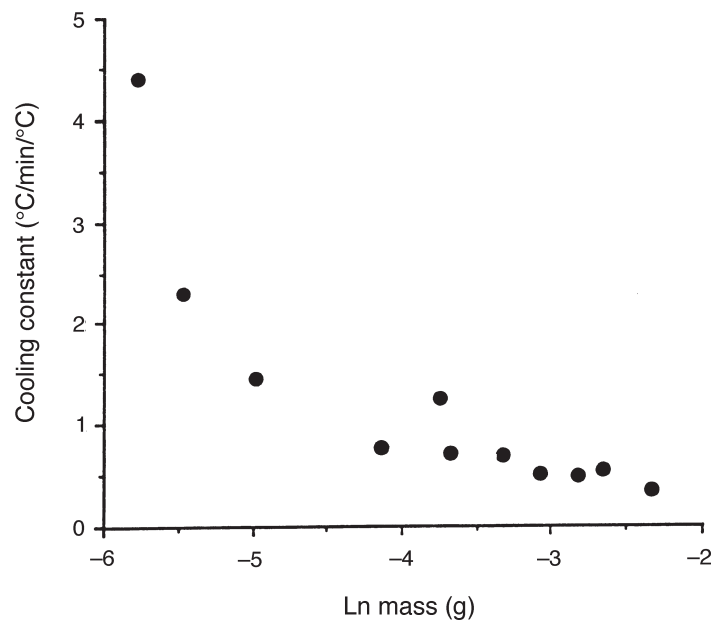

(C) 1999 British Ecological Society, Functional Ecology, 13, 711-724
Fig. 2. Cooling constant vs $\ln$ (dry mass) for 11 bee size groups (species/sexes) in interior Alaska. The taxa used in this analysis are denoted by an asterisk in Table 1.
McGinley \& Danforth (1994) and the phylogeny presented in Michener (1974), as modified for Anthophoridae/Apidae by Roig-Aisina \& Michener (1993) (Fig. 1). For this analysis branch lengths were assumed equal. Males and workers were not included in the analysis except in two cases where female/queen data were unavailable for the species (Andrena thaspii, Bombus alboanalis). This analysis calculates, for each variable, the differences between the values of paired sister taxa in the phylogeny. It also calculates differences between estimated values of phylogenetically paired ancestors. The variables are related to one another by regressing the values of the paired differences for one variable on the corresponding values of the other variable, with the regression constrained through the origin (see Purvis \& Rambaut 1995).

To test whether bumble-bees are better thermoregulators than solitary bees after the effect of size has been removed, analysis of covariance of thermoregulatory performance, thoracic temperature elevation and minimum $T_{\text {th }}$ at takeoff was conducted, using body mass as a covariate. Similar analyses were conducted to look for size-corrected thermoregulatory differences between worker and queen Bombus. Because bumblebees generally cluster at the upper end of the size range, there is the potential for accelerating non-linearity of the size-thermoregulatory ability relationship to cause overestimation of bumble-bee thermoregulatory ability and mistaken rejection of the null hypothesis. However, consideration of basic biophysical principles suggests that any non-linear relationship is more likely to be decelerating (i.e. thermoregulatory ability improves asymptotically with size) and thus overestimation of bumble-bee thermoregulatory ability is unlikely. Another weakness of the ANCOVA approach is that the covariate is estimated 'naïvely', that is without benefit of phylogenetic information. For reasons discussed below, we do not consider this a serious problem, but it should be kept in mind.

\section{Results}

\section{COOLING CURVES}

Cooling curves for individuals of all species showed exponential decay ( $T_{\text {th }} v s$ time). Across the species studied, the cooling constants (the slopes of the loglinearized cooling curves) decrease approximately exponentially with increasing mean dry body mass (Fig. 2). Thus, small bees lose heat very quickly and large bees lose heat comparatively slowly as would be expected from biophysical principles (e.g. Wathen et al. 1971; Porter et al. 1994). No size group showed a conspicuous departure from this trend.

\section{THERMOREGULATORY PERFORMANCE INDEX}

The regression of $T_{\text {th }}$ against $T_{\mathrm{e}}$ for each species shows 
Thermoregulation of Alaskan bees how well it regulates $T_{\mathrm{th}}$. The relationship between $T_{\mathrm{th}}$ and $T_{\mathrm{e}}$ is depicted in Fig. 3 for a small solitary bee, Hylaeus ellipticus (dry mass $=0.0042 \mathrm{~g}$, fresh mass $\approx 0.012 \mathrm{~g}$ ), a moderate-size solitary bee, Megachile giliae (dry mass $=0.0357 \mathrm{~g}$, fresh mass $\approx 0.102 \mathrm{~g}$ ), and a large social bee, Bombus frigidus (queen; dry mass $=0.0899 \mathrm{~g}$, fresh mass $\approx 0.257 \mathrm{~g}$ ). The slope of the line described by $T_{\text {th }} v s T_{\mathrm{e}}$ for each species is used as its thermoregulatory performance index (recall that near 1.0 is poor regulation, near zero is good regulation). The thermoregulatory performance index is 0.96 for

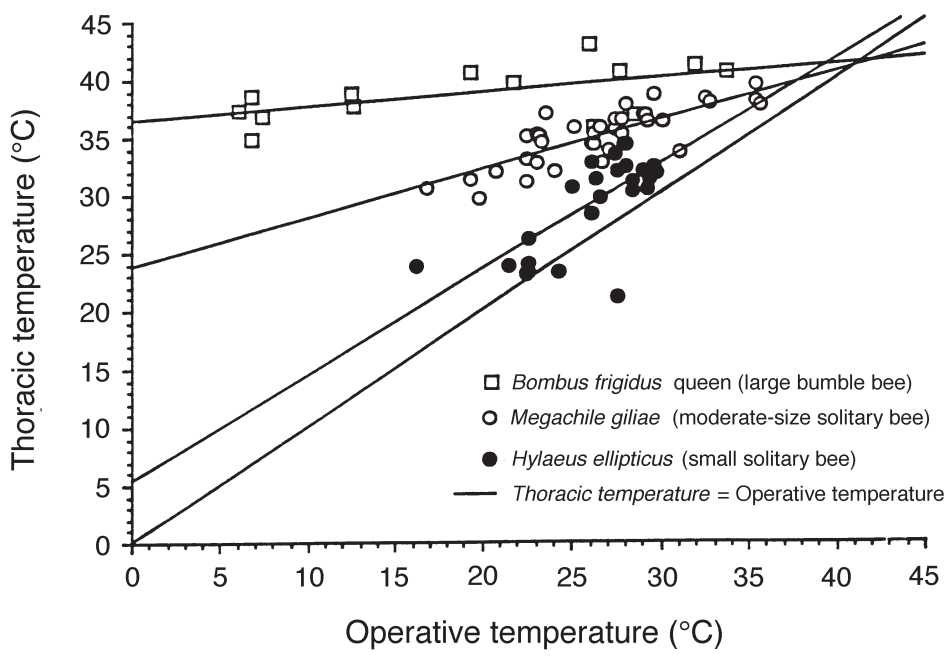

Fig. 3. Thoracic temperature $v s$ operative temperature for three representative bee species. Each point represents a measurement on an individual bee. Thermoregulatory capabilities are shown for a small bee, a moderate-size bee and a large bee. The isothermal line $\left(T_{\mathrm{th}}=T_{\mathrm{e}}\right)$ is included for reference.

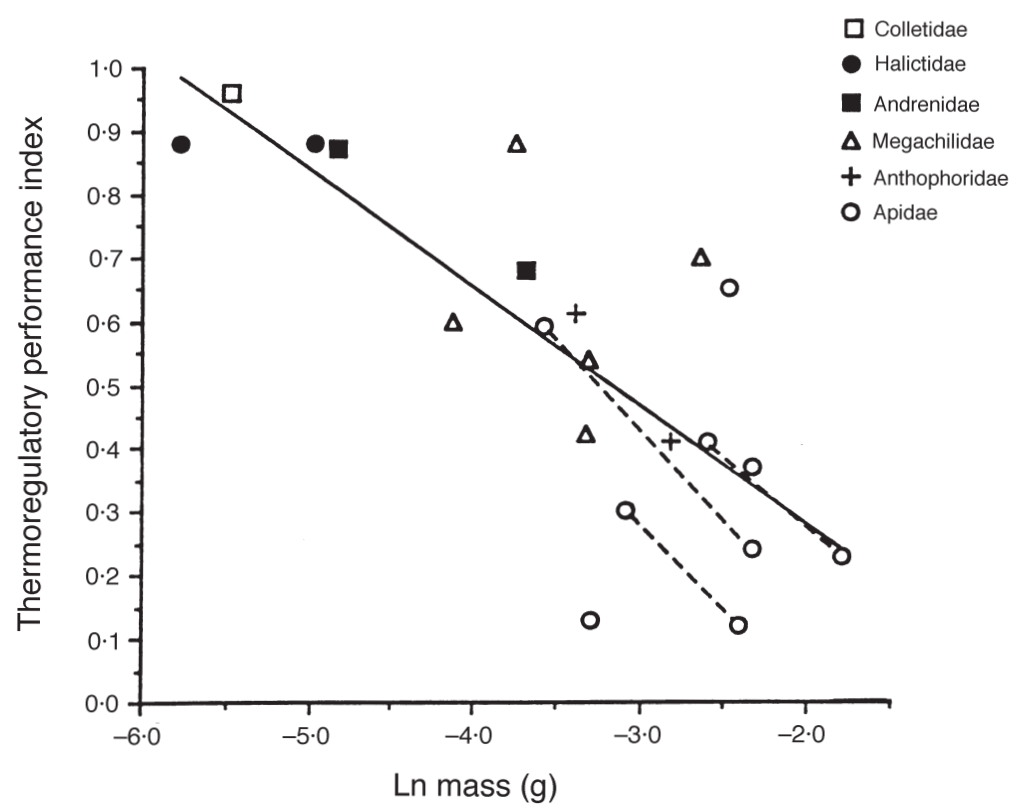

Fig. 4. Thermoregulatory performance index $v s$ ln dry mass. Each point represents a size group. The thermoregulatory capability is associated with size $\left(\mathrm{Y}=-0.187 x-0.095, r^{2}=0.60, P=0.0001\right)$. Queen and worker bumble-bees of the same species are connected by dashed lines.
Hylaeus ellipticus, $0 \cdot 42$ for Megachile giliae, and $0 \cdot 12$ for Bombus frigidus (see Fig. 3). The thermoregulatory performance indices for Bombus frigidus and Hylaeus ellipticus are the lowest and highest, respectively, of the 21 taxa measured (Table 1).

'Naïve' regression analyses across species and families and analysis of independent contrasts all showed significant negative relationships between the thermoregulatory performance index and dry mass (Table 2, Figs 4 and 5), and the estimated slopes of the relationships did not differ significantly across methods (Table 2). The thermoregulatory performance index was also significantly negatively correlated with thoracic volume $\left(r^{2}=0.59, P<0.001, N=21\right)$ and wing loading $\left(r^{2}=0.49, P<0.001, N=21\right)$. These results indicate that body size alone explains much of the variation in bee thermoregulatory ability (with and without the effects of phylogeny being removed) and that large bees are generally better at regulating body temperature than small bees.

\section{ELEVATION OF THORACIC TEMPERATURE}

$T_{\text {th }}$ elevation indices ranged from $1.9{ }^{\circ} \mathrm{C}$ to $31.1{ }^{\circ} \mathrm{C}$ (Table 1). 'Naïve' regression analyses across species and families and analysis of independent contrasts all showed significant positive relationships between the elevation of thoracic temperature and dry mass (Table 2, Figs 6 and 7). Furthermore, the estimated slopes of the relationships were generally similar and not statistically different across analyses (Table 2). The $T_{\text {th }}$ elevation index was also significantly positively correlated with thoracic volume $\left(r^{2}=0.73, P<0.001\right)$ and wing loading $\left(r^{2}=0 \cdot 60, P<0 \cdot 001\right)$. These results indicate that body size alone explains much of the variation in bees' ability to maintain thoracic temperature above the environmental temperature and that large bees are generally better at maintaining elevated thoracic temperature than small bees.

\section{MINIMUM MUSCLE TEMPERATURE FOR TAKEOFF}

The minimum $T_{\text {th }}$ at flight initiation for each group ranged from 17.0 to $35.7^{\circ} \mathrm{C}$ (Table 1). 'Naïve' regression analysis across species and families and analysis of independent contrasts all showed significant (or nearly significant) positive relationships between dry mass and the minimum observed $T_{\text {th }}$ at which bees were observed to take off (Table 2, Figs 8 and 9). Furthermore, the estimated slopes of the relationships were generally similar and not statistically different across analyses (Table 2). Minimum $T_{\text {th }}$ for flight initiation was also significantly positively correlated with thoracic volume $\left(r^{2}=0.69, P<0.001\right)$ and wing loading $\left(r^{2}=0.65, P<0.001\right)$. These results indicate that body size can explain much of the variation in minimal thoracic temperature at which bees can fly and that small bees can generally fly with a lower $T_{\text {th }}$ than large bees. 
J. A. Bishop \& W. S. Armbruster

Table 2. Comparison of results of 'naïve' among-species and among-family regressions and analyses of phylogenetically based independent contrasts

\begin{tabular}{|c|c|c|c|c|}
\hline Analysis & $r^{2}$ & $n$ & $P$ & $\begin{array}{l}\text { Regression coefficient } \\
\text { (95\% confidence interval) }\end{array}$ \\
\hline \multicolumn{5}{|c|}{ Thermoregulatory performance index $v s$ dry mass } \\
\hline Among size groups & $0 \cdot 60$ & 21 & $<0 \cdot 001$ & $-0.186(-0.259$ to $-0 \cdot 114)$ \\
\hline Among families & $0 \cdot 92$ & 6 & $0 \cdot 002$ & $-0 \cdot 190(-0.265$ to $-0 \cdot 114)$ \\
\hline Independent contrasts & $0 \cdot 39$ & 11 & $0 \cdot 029$ & $-0.129(-0.228$ to -0.030$)$ \\
\hline \multicolumn{5}{|c|}{ Temperature elevation of thorax $v s$ dry mass } \\
\hline Among size groups & 0.71 & 21 & $<0 \cdot 001$ & $6 \cdot 25(4 \cdot 33$ to $8 \cdot 16)$ \\
\hline Among families & $0 \cdot 83$ & 6 & $0 \cdot 012$ & $5 \cdot 29(1.95$ to $7 \cdot 70)$ \\
\hline Independent contrasts & $0 \cdot 52$ & 11 & $0 \cdot 009$ & $4 \cdot 29(1.73$ to $6 \cdot 85)$ \\
\hline \multicolumn{5}{|c|}{ Minimum thoracic temperature at takeoff } \\
\hline Among size groups & $0 \cdot 69$ & 21 & $<0 \cdot 001$ & $4 \cdot 35(2.96$ to $5 \cdot 73)$ \\
\hline Among families & 0.75 & 6 & $0 \cdot 025$ & $4.10(0.86$ to 7.70$)$ \\
\hline Independent contrasts & $0 \cdot 30$ & 11 & 0.064 & $2.51(0.15$ to 4.87$)$ \\
\hline
\end{tabular}

\section{THERMOREGULATION BY BUMBLE-BEES VS} SOLITARY BEES

Bumble-bees fell generally on or below the regression of thermoregulatory performance on dry mass (Fig. 4), and thus tended to be slightly better thermoregulators than predicted by size. There was no evidence that the slopes of the thermoregulatory performance-mass relationships differed between solitary bees and bumble-bees $\left(F_{1,17}=0.40, P=0.54\right)$. Analysis of covariance (ANCOVA) indicated a small but significant difference in thermoregulatory ability of bumble-bees and solitary bees after the effect of size was removed $\left(F_{1,18}=4 \cdot 55, P=0 \cdot 047\right)$. Thus bumblebees appear to be slightly better thermoregulators (as measured by this index) than solitary bees, even after

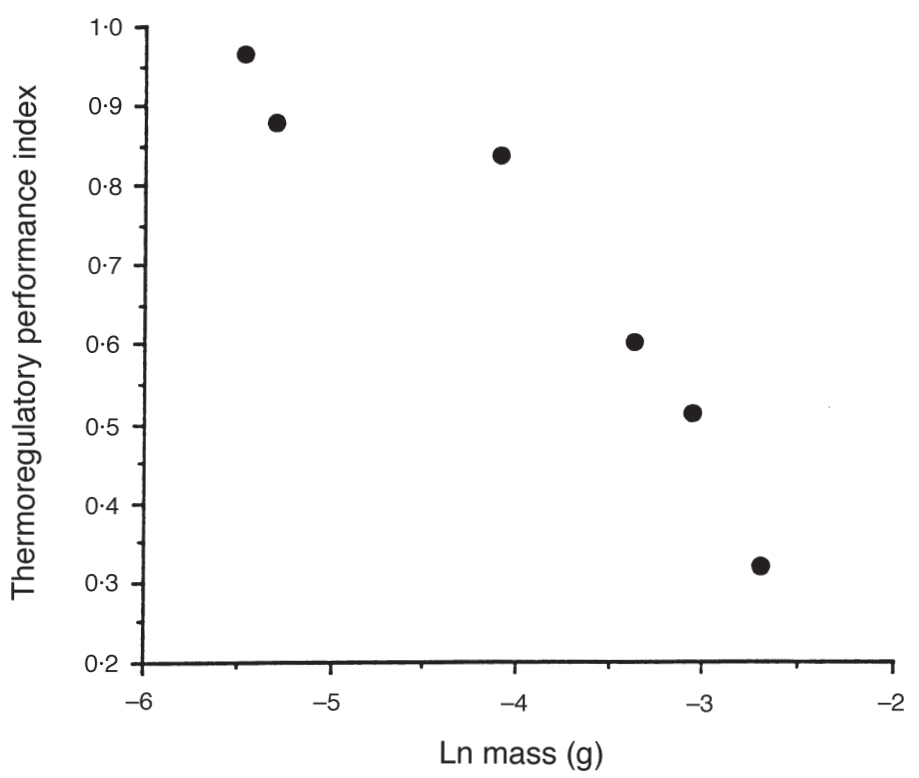

Fig. 5. Thermoregulatory performance index $v s$ ln dry mass at the family level. Each point represents the means of one family. The ability to regulate $T_{\text {th }}$ is correlated with mass at the family level (Kendall's tau $=1, z=-2 \cdot 82, P=0 \cdot 002$ ). the effect of size differences has been removed. There were no apparent differences in the slopes of relationships between mass and thermoregulatory performance for worker and queen bumble-bees $\left(F_{1,5}=0 \cdot 12, P=0 \cdot 89\right)$, nor in their size-corrected thermoregulatory abilities (see Fig. 3; ANCOVA, $\left.F_{1,6}=1 \cdot 73, P=0 \cdot 21\right)$.

Bumble-bees fell generally above the regression of $T_{\text {th }}$ elevation on dry mass and thus appeared to be better temperature elevators than predicted by size (Fig. 6). The slopes of the regression of $T_{\text {th }}$ elevation on dry mass for bumble-bees and solitary bees were not significantly heterogeneous $\left(F_{1,17}=1.56\right.$, $P=0.23$ ), and ANCOVA indicated that bumble-bees were better at maintaining elevated thoracic temperature than solitary bees, even after the effect of larger body size had been removed $\left(F_{1,18}=12 \cdot 59\right.$, $P=0.002)$. There were no apparent differences in the slopes of the mass-temperature elevation relationships for worker and queen bumble-bees $\left(F_{1,5}=1 \cdot 25, P=0 \cdot 31\right)$, nor in their size-corrected ability to elevate thoracic temperature $\left(F_{1,6}=1 \cdot 04\right.$, $P=0 \cdot 37)$.

Bumble-bees had more positive than negative residuals off the regression of minimum takeoff $T_{\text {th }}$ on dry mass (Fig. 8). ANCOVA showed the trend toward higher $T_{\text {th }}$ than predicted by size to be marginally significant $\left(F_{1,18}=3 \cdot 68, P=0 \cdot 07\right.$; the slopes of the mass-takeoff $T_{\text {th }}$ relationships were not significantly heterogeneous; $\left.F_{1,17}=1 \cdot 95, P=0 \cdot 18\right)$. There were no apparent differences in the slopes of the mass-takeoff $T_{\text {th }}$ relationships $\left(F_{1,5}=0.27, P=0.77\right)$ or in the size-corrected takeoff $T_{\text {th }}$ of worker and queen bumble-bees $\left(F_{1,6}=0 \cdot 26, P=0.77\right)$.

\section{Discussion}

Both measures of bee thermoregulatory capability (the slope and the elevation of the relationship 
Thermoregulation of Alaskan bees between thoracic temperature and environmental temperature) were correlated with the three measures of size (dry body mass, thoracic volume and wing-loading). These correlations were apparent in species comparisons, family comparisons and analysis of independent contrasts. Large bees had generally better thermoregulatory capabilities than smaller bees. The minimum observed muscle temperature at takeoff was also positively correlated with body mass. This corre-

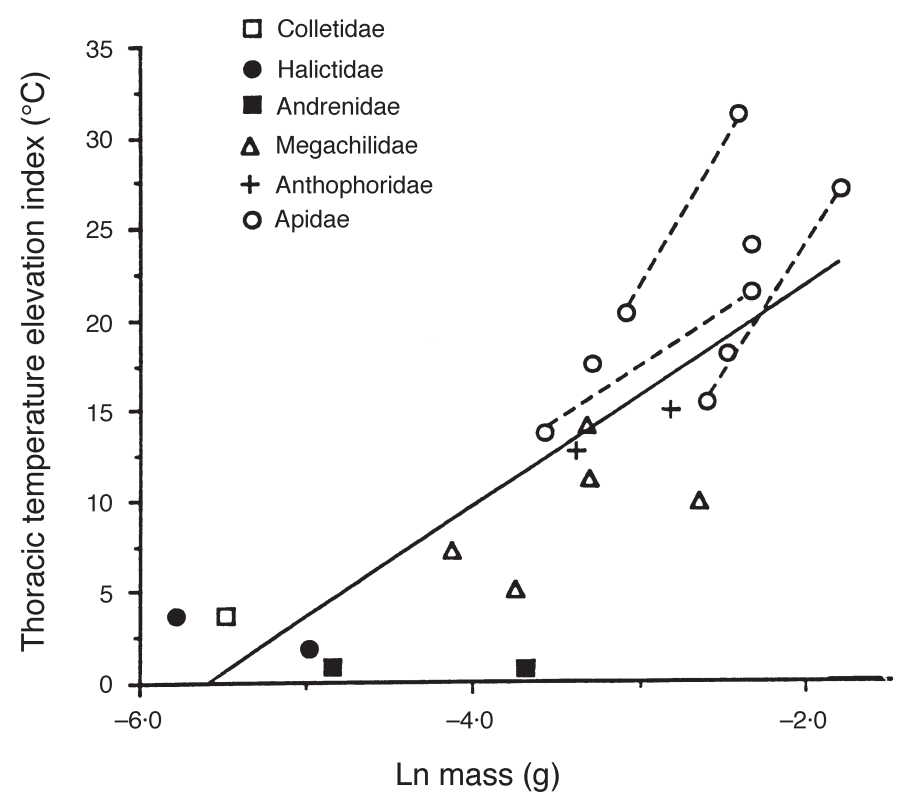

Fig. 6. Thoracic temperature elevation index $v s \ln$ dry mass. Each point represents a size group. The ability to elevate $T_{\text {th }}$ is significantly associated with the natural log of mass $\left(Y=5 \cdot 98 x+33 \cdot 72, r^{2}=0 \cdot 67, P=0 \cdot 0001\right)$. Queen and worker bumble-bees of the same species are connected by dashed lines.

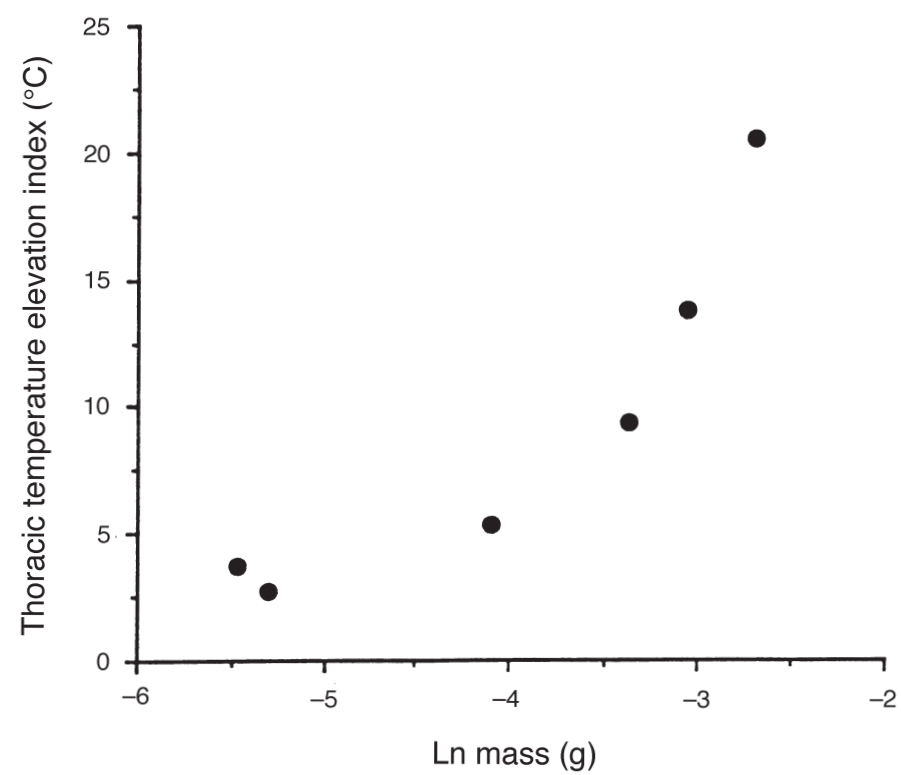

Fig. 7. Thoracic temperature elevation index $v s \ln$ dry mass at the family level. Each point represents the means of one family. The ability to elevate $T_{\text {th }}$ is significantly associated with the natural $\log$ of mass (Kendall's tau $=0 \cdot 87, z=2 \cdot 44, P=0 \cdot 02$ ). lation was also significant at species and family levels, and marginally significant in the independentcontrast analysis. In general, small bees could initiate flight at lower thoracic temperatures than large bees.

Some of these results could be predicted from simple biophysical models that incorporate rate of heat loss and gain in relation to pelage and thoracic shape and diameter of each bee species (see Wathen et al. 1971; Kingsolver 1979, 1983; Porter et al. 1973, 1994; Grant \& Porter 1992; Helmuth 1998). However, one difficulty with this approach is deciding whether to model bees as basically endothermic or ectothermic (compare, for example, Porter et al. 1994 and Helmuth 1998). Our results indicate that bees display continuous variation in degree of endothermy, ranging from endothermy in bumble-bees to ectothermy in the smallest solitary bees; more refined biophysical models would need to address this variation.

\section{RELATIONSHIP BETWEEN THERMOREGULATORY CAPABILITY AND SIZE}

The observed relationship between thermoregulatory performance index and body mass shows a continuum between good thermoregulators and thermal conformers (see Fig. 3). Bumble-bees showed the greatest ability to regulate $T_{\mathrm{th}}$ of any bees in interior Alaska. Several intermediate-size bees (e.g. Megachile spp., Anthophora bomboides, Osmia spp.) showed intermediate abilities to regulate $T_{\mathrm{th}}$. Osmia sp. nov. was the smallest bee to show appreciable ability to regulate $T_{\text {th }}$ (thermoregulatory performance index $=0.60$, mean dry mass $=0.016 \mathrm{~g}$ ). Bees smaller than $0 \cdot 015 \mathrm{~g}$ dry mass (e.g. Evylaeus comagenensis, Hylaeus ellipticus and Dialictus ruidosensis) showed no appreciable ability to regulate $T_{\mathrm{th}}$. These results are largely in agreement with previous studies (e.g. Stone \& Willmer 1989b; Stone 1993a,b).

The ability to elevate $T_{\mathrm{th}}$ was used as another measure of thermoregulatory capability. The positive relationship between $T_{\mathrm{th}}$ elevation index and size in bees is consistent with studies in beetles (Bartholomew \& Heinrich 1978) and moths (Bartholomew \& Heinrich 1973). Also, values for $T_{\text {th }}$ at $T_{\mathrm{a}}=22{ }^{\circ} \mathrm{C}$ in this study were similar to values of similar sized bees in other parts of the world (Stone \& Willmer 1989b). The positive relationship between $T_{\text {th }}$ elevation and mass is also consistent with the negative relationship between the thermoregulatory performance index and mass.

It appears that bumble-bees are better thermoregulators than solitary bees mostly because of their larger size. The amount of variance explained by the covariate (size) in the ANCOVAs was much greater than that explained by class (bumble-bee $v s$ solitary bee). Size within class explained $31 \%$ of the variance in thermoregulatory performance index, whereas class explained only $14 \%$. Size within class explained 39\% of the variance in elevation of thoracic temperature, whereas class explained $25 \%$. ANCOVA of both measures 


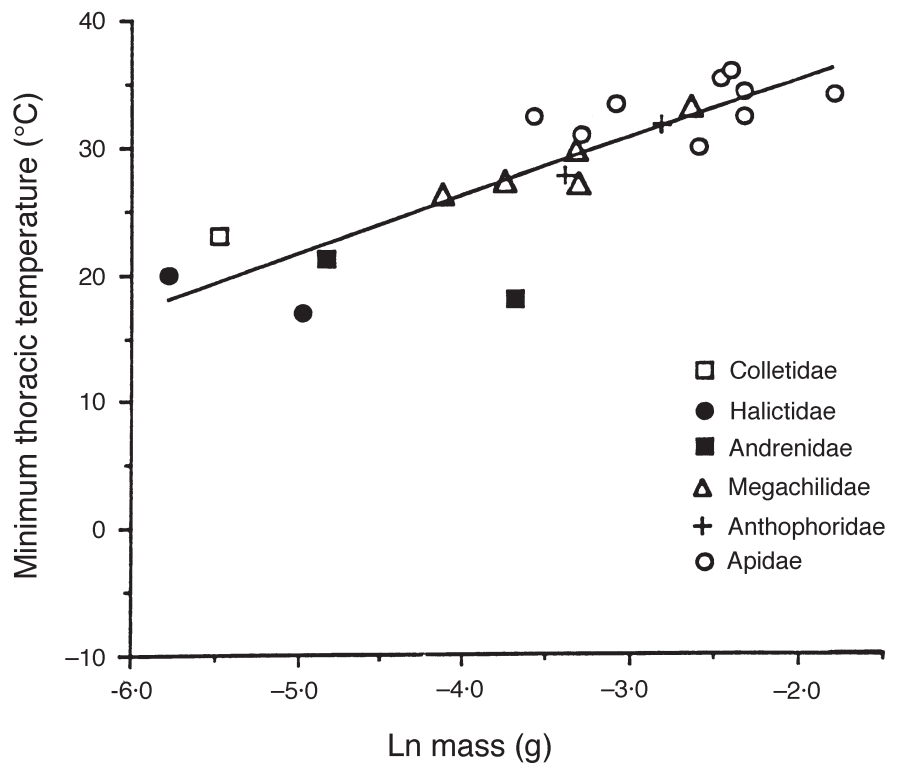

Fig. 8. Minimum $T_{\text {th }}$ for flight $v s$ ln dry mass. Each point represents a size group. The minimum $T_{\text {th }}$ at which bees were observed to fly increases with the natural log of body mass $\left(Y=5 \cdot 98 x+33 \cdot 72, r^{2}=0 \cdot 67, P=0.0001\right)$.

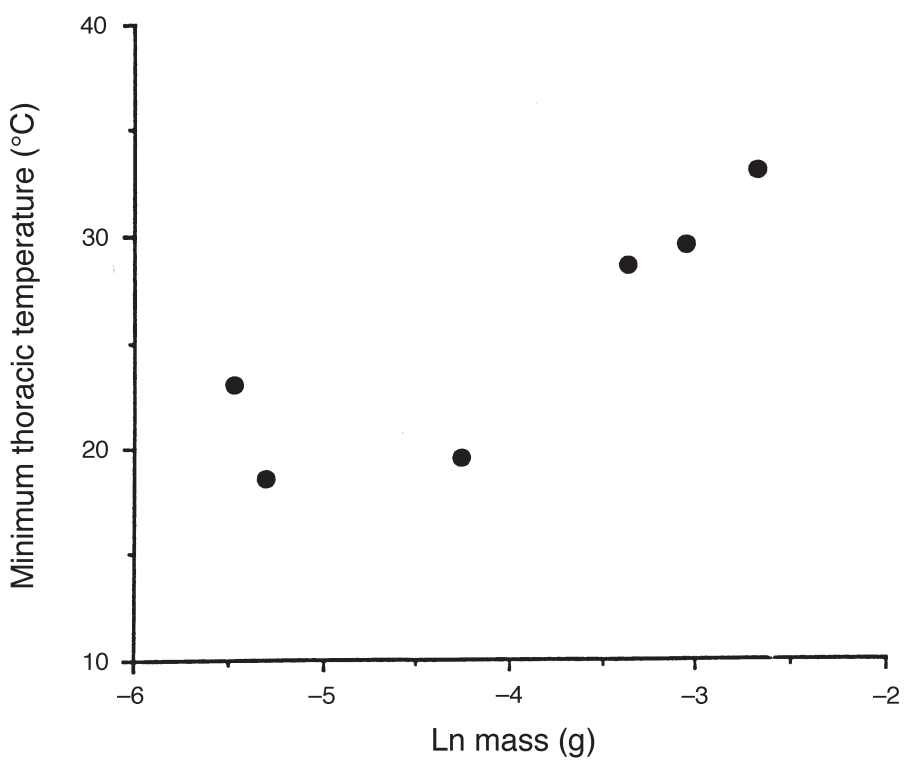

Fig. 9. Minimum $T_{\text {th }}$ for flight $v s \ln$ dry mass at the family level. Each point represents the means of one family. The minimum $T_{\text {th }}$ at which bees were observed to fly increases with the natural $\log$ of body mass (Kendall's tau $=0.73, z=2 \cdot 07, P=0 \cdot 032$ ). in interior Alaska, and at high latitudes and elevations in general.

$T_{\text {th }}$ regulation, $T_{\mathrm{th}}$ elevation and minimum $T_{\mathrm{th}}$ for takeoff by queens and workers of three Bombus species were measured (see Figs 4 and 6). Queens regulated and elevated $T_{\text {th }}$ better than workers, and required a higher $T_{\text {th }}$ for flight in all three species studied (Bombus frigidus, B. flavifrons and B. occidentalis). However, the difference in thermoregulatory capability in these three species varied between castes in a manner largely consistent with the overall relationship between thermoregulatory capability and mass. This observation was confirmed by the ANCOVA, which showed no significant differences in the thermal biology of queens and workers after correcting for body mass. This finding contrasts with Heinrich \& Heinrich (1983a), who found that queens and workers fly with the same $T_{\text {th }}$ despite the disparity in size. They suggested that worker bumble-bees are genetically constrained to fly at the same $T_{\text {th }}$ 'set points' as queens, and thus workers fly with the thermal attributes of much larger bees. Our observation that queens have a higher $T_{\text {th }}$ for flight initiation (consistent with their size) suggests the absence of a genetically constrained set point common across both castes. However, failure to find a size-corrected difference in thermoregulation of queens and workers does not alone demonstrate its absence.

The relationship between cooling constant and dry mass appears to be a negative exponential function (Fig. 2). Below $\approx 0.015 \mathrm{~g}$ dry mass $(-4.2 \mathrm{~g} \ln$ mass) the cooling constant rises quickly, and bees show no appreciable ability to regulate $T_{\mathrm{th}}$ independently of $T_{\mathrm{e}}$. Thus small bees may be poorer thermoregulators because they are unable to retain metabolically generated heat. Studies by Church (1960), Chappell (1982) and May \& Casey (1983) also suggest that this phenomenon is the result of small size rather than less extensive pubescence in small bees.

This study is in agreement with others showing that large bees can generally regulate and elevate $T_{\text {th }}$ better than small bees (e.g. Stone \& Willmer 1989b; Stone 1993a,b). It is also consistent with the observation that large queen bumble-bees forage in much cooler conditions than smaller workers (Heinrich \& Heinrich 1983a), and bumble-bees can forage in cooler habitats than smaller solitary bees (Armbruster \& Guinn 1989). There would thus be a clear thermoregulatory advantage for solitary bees at high latitudes (and elevations) to be relatively large. However, solitary bees in the Arctic and subarctic are generally smaller than their relatives in the tropics (Armbruster \& Guinn 1989; Roubik 1989; O’Toole \& Raw 1991). Indeed the largest bees (e.g. Chalicodoma, Xylocopa, Eulaema), which dwarf bumble-bees, are tropical or subtropical (Roubik 1989). This observation suggests that there are other constraints on body size at high latitudes, such as resource availability, the rate of development and time available for growth. At high 
721

Thermoregulation of Alaskan bees latitudes bees must develop in one short growing season (or complementary parts of two growing seasons), and this limits the size they can attain (see Adolph \& Porter 1996). Thus the length of growing season at high latitudes probably constrains body size of solitary bees, and this in turn constrains thermoregulatory ability and amount of time to forage. Sociality and temporal variability in body size may be one way to overcome the thermal constraints on foraging in cool climates, e.g. in Bombus, larger individuals (queens) forage during colder parts of the season.

\section{RELATIONSHIP BETWEEN SIZE AND MINIMUM $T_{\mathrm{TH}}$ NECESSARY FOR TAKEOFF}

A positive relationship was found between the minimum $T_{\text {th }}$ necessary for initiation of flight and size and wing loading in bees. Andrena frigida and Evylaeus comagenensis may deviate from this relationship in that they can fly with a $T_{\text {th }}$ lower than would be predicted from size and wing loading (Fig. 8, lower and $\square$ ). Both species forage very early in the season when $T_{\mathrm{e}}$ rarely reaches $20{ }^{\circ} \mathrm{C}$. These two species may have evolved some attribute (e.g. enzyme activities adapted to lower temperatures) that allows them to fly with unusually low $T_{\mathrm{th}}$, and this deserves more study. In general, the reduction of minimum $T_{\text {th }}$ for flight with size allows small bees more foraging time in cool climates, and may be a second way to partially overcome the constraints of size, thermal ecology and life history discussed above.

\section{MEASURING THERMOREGULATORY CAPABILITY AND COMPARING SPECIES}

Thermoregulatory capability was measured by regressing $T_{\text {th }}$ against $T_{\mathrm{e}}$ instead of $T_{\mathrm{a}}$ as has been done in most previous studies on insect thermoregulation (e.g. Heinrich 1971, 1972a,b, 1975, 1984; May \& Casey 1983; Chappell 1984; Dyer \& Seeley 1987; Armbruster \& McCormick 1990; Underwood 1991). The use of $T_{\mathrm{e}}$ has two advantages over using $T_{\mathrm{a}}$. First, it is a more accurate measure of the thermal environment an insect actually experiences in nature (Bakken 1976, 1980, 1992). Second, it allows accurate comparison of $T_{\text {th }}$ of insects under different microclimatic conditions (e.g. sun $v s$ shade) because $T_{\mathrm{e}}$ integrates radiative and convective heat exchanges in a single measurement. While the measurement of $T_{\mathrm{e}}$ is especially useful in studies of microclimatic influences on insect activity in cold climates, it has also been informative in studies of insect activity in warm temperate and tropical regions (Chappell 1982; Bakken 1992; O’Neill \& Kemp 1992; Armbruster \& Berg 1994; Rutowski, Demlong \& Leffingwell 1994; Ward \& Seely 1996; Frears, Chown \& Webb 1997; Schultz 1998).

The relationship between size and three measures of thermal biology was estimated by treating each size group (species) as an individual observation. Implicit in this procedure is the assumption that the thermal biology of each species is independent and the relationship is similar at all levels of phylogenetic (taxonomic) organization. If species are not independent with respect to thermal biology, treating each species as a separate point inflates the degrees of freedom and confounds phylogenetic similarity with ecophysiological similarity. The risk is that species may show an apparent association between thermoregulatory capability and size because of common ancestry rather than a functional relationship between the variables (Felsenstein 1985; Pagel \& Harvey 1991).

To test the likelihood that the apparent relationships were created by phylogenetic effects, the amongspecies comparisons were compared with amongfamily comparisons and analysis of phylogenetically based independent contrasts (Felsenstein 1985; Pagel 1992). The correlation and regression coefficients were statistically indistinguishable across the three analyses. This suggests that the relationship between size and thermoregulatory abilities is not strongly influenced by phylogenetic history in these bees, but rather is more strongly influenced by physical parameters of the bee (and the laws of thermal physics). However, it would be unwise to ignore phylogenetic effects in comparative physiological studies (Huey 1987). Indeed the greater ability of Bombus to maintain elevated $T_{\text {th }}$ than would be expected from its body mass alone is correlated with phylogeny.

It was found that the differences in thermoregulatory capabilities between conspecific queen and worker bumble-bees and between male and female Anthophora bomboides were adequately explained by their size differences (Figs 4, 6 and 8). However, our power to detect sex- or caste-related differences was not great, because the sample size was small and it was not the main aim of the study. In contrast, Stone (1993a,b) found significant differences in thermoregulatory abilities between sexes of Anthophora after controlling for effect of body size.

Our results suggest that thermoregulatory capability is strongly influenced by the biophysical constraints of body size, and in the subarctic, at least, adaptive divergence among solitary bees has not greatly altered this pattern. Bombus shows evidence of having adapted to cooler climates by slightly improved thermoregulation. There may be other groups of bees not conforming to the general size-thermoregulation relationship we have detected, and future studies may identify these. Nevertheless, body size appears to be the primary factor determining the thermoregulatory abilities of bees.

\section{Acknowledgements}

Karen Max, Mamoru Matsuki, Mike Smith, Matt Ayres, Kent Schwaegerle, Jan Shellman-Reeve, Andi Lloyd, Graham Stone and Andy Purvis provided help
Functional Ecology, 13, 711-724 
with technical, conceptual or analytical problems. The following authorities provided determinations of bee specimens: Robbin Thorp (Bombus), Roy Snelling (Hylaeus), Richard Rust (Osmia), Terry Griswold (Megachilidae), Charles Michener (Panurginus), Robert Brooks (Anthophora), Wallace LaBerge (Andrena), Laurence Packer (Evylaeus) and George Eickwort (Halictidae). Don Chase and Penny Knuckles of the Yukon-Charley National Preserve provided access and logistical support to the 1991 field site. The logistical support and hospitality of Errol and Rebecca Wilson made the 1991 field season truly pleasurable. The staff at the National Weather Service office in Fairbanks was helpful in providing weather records. Helpful comments on this manuscript were made by Andi Lloyd, Steve MacLean, Mike Castellini, Mark Chappell, Steve Adolph, Ray Huey, Rex Cocroft, Bill Wcislo, George Eickwort, Thomas Hansen, Warren Porter, Graham Stone and several anonymous reviewers.

\section{References}

Adolph, S.C. \& Porter, W.G. (1996) Growth, seasonality, and lizard life histories: age and size at maturity. Oikos 77, 267-278.

Armbruster, W.S. (1988) Multilevel comparative analysis of morphology, function, and evolution of Dalechampia blossoms. Ecology 69, 1746-1761.

Armbruster, W.S. (1992) Phylogeny and the evolution of plant-animal interactions. Bioscience 42, 12-20.

Armbruster, W.S. (1996) Evolution of floral morphology and function: an integrated approach to adaptation, constraint, and compromise in Dalechampia (Euphorbiaceae). Floral Biology (eds D. Lloyd \& S. C. H. Barrett), pp. 241-272. Chapman \& Hall, New York.

Armbruster, W.S. \& Berg, E.E. (1994) Thermal ecology of male euglossine bees in a tropical wet forest: fragrance foraging in relation to operative temperature. Biotropica 26, 50-60.

Armbruster, W.S. \& Guinn, D.A. (1989) The solitary bee Alaska: flower associations, habitat use, and phenology. Journal of the Kansas Entomological Society 62, 468-483.

Armbruster, W.S. \& McCormick, K.D. (1990) Diel foraging patterns of male euglossine bees: ecological causes and evolutionary response by plants. Biotropica 22, 160-171.

Armbruster, W.S. \& McGuire, A.D. (1991) Experimental assessment of reproductive interactions between sympatric Aster and Erigeron (Asteraceae) in interior Alaska. American Journal of Botany 78, 1449-1457.

Baird, J.M. (1986). A field study of thermoregulation in the carpenter bee Xylocopa virginica virginica (Hymenoptera: anthophoridae). Physiological Zoology 59, 157-168.

Bakken, G.S. (1976) A heat transfer analysis of animals: unifying concepts and the application of metabolism chamber data to field ecology. Journal of Theoretical Biology 60, 337-384.

Bakken, G.S. (1980) The use of standard operative temperature in the study of the thermal energetics of birds. Physiological Zoology 53, 108-119.

(C) 1999 British Ecological Society, Functional Ecology, 13, 711-724

tive and standard operative temperatures in ecology. American Zoologist 32, 194-216. fauna (Hymenoptera: apoidea) of interior and arctic

Barnes, B.M., Barger, J.L., Seares, J., Tacquard, P.C. \& Zuercher, G.L. (1996) Overwintering in yellowjacket queens (Vespula vulgaris) and green stinkbugs (Elasmostethus interstinctus) in subarctic Alaska. Physiological Zoology 69, 1469-1480.

Bartholomew, G.A. (1981) A matter of size: an examination of endothermy in insects and terrestrial vertebrates. Insect Thermoregulation (ed. B. Heinrich), pp. 46-78. Wiley, New York.

Bartholomew, G.A. \& Heinrich, B. (1973) A field study of flight temperatures in moths in relation to body weight and wing loading. Journal of Experimental Biology 58, 123-135.

Bartholomew, G.A. \& Heinrich, B. (1978) Endothermy in African dung beetles during flight, ball making, and ball rolling. Journal of Experimental Biology 73, 65-83.

Bell, G. (1989) A comparative method. American Naturalist 133, 553-571.

Casey, T.M. (1992) Biophysical ecology and heat-exchange in insects. American Zoologist 32, 225-237.

Casey, T.M. \& Joos, B.A. (1983) Morphometrics, conductance, thoracic temperature, and flight energetics of noctuid and geometrid moths. Physiological Zoology 56, 160-173.

Chappell, M.A. (1982) Temperature regulation of carpenter bees (Xylocopa californica) foraging in the Colorado Desert of southern California. Physiological Zoology 55, 267-280.

Chappell, M.A. (1984) Temperature regulation and energetics of the solitary bee Centris pallida during foraging and intermale mate competition. Physiological Zoology 57, 215-225.

Church, N.S. (1960) Heat loss and the body temperatures of flying insects. II. Heat conduction within the body and its loss by radiation and convection. Journal of Experimental Biology 37, 186-213.

Cooper, P.D., Schaffer, W.M. \& Buchmann, S.L. (1985) Temperature regulation of honey bees (Apis mellifera) foraging in the Sonoran Desert. Journal of Experimental Biology 114, 1-15.

Corbet, S.A., Fussell, M., Ake, R., Fraser, A., Gunson, C., Savage, A. \& Smith, K. (1993) Temperature and the pollinating activities of social insects. Ecological Entomology 18, 17-30.

Dyer, F.F. \& Seeley, T.D. (1987) Interspecific comparisons of endothermy in honey-bees (Apis): deviations from the expected size-related patterns. Journal of Experimental Biology 127, 1-26.

Edwards, M.E. \& Armbruster, W.S. (1989) A steppe-tundra transition on Kathul Mountain, Alaska. Arctic and Alpine Research 21, 296-304.

Feller, P. \& Nachtigall, W. (1989) Flight of the honey bee II. Inner- and surface thorax temperatures and energetic criteria, correlated to flight parameters. Journal of Comparative Physiology B 158, 719-727.

Felsenstein, J. (1985) Phylogenies and the comparative method. American Naturalist 125, 1-15.

Frears, S.L., Chown, S.L. \& Webb, P.I. (1997) Behavioural thermoregulation in the mopane worm (Lepidoptera). Journal of Thermal Biology 22, 325-330.

Grafen, A. (1989) The phylogenetic regression. Philosophical Transactions of the Royal Society, Series B 326, 119-157.

Grant, B.W. \& Porter, W.P. (1992) Modeling global macroclimatic constraints on ectotherm energy budgets. American Zoologist 32, 154-178.

Harvey, P.H. \& Pagel, M.D. (1991) The Comparative Method in Evolutionary Biology. Oxford University Press, Oxford.
Heinrich, B. (1971). Temperature regulation of the sphinx 
Thermoregulation of Alaskan bees moth, Maduca sexta I. Flight energetics and body temperature during free and tethered flight. Journal of Experimental Biology 54, 141-152.

Heinrich, B. (1972a) Energetics of temperature regulation and foraging in a bumblebee. Bombus terricola Kirby. Journal of Comparative Physiology 77, 49-64.

Heinrich, B. (1972b) Patterns of endothermy in bumblebee queens, drones and workers. Journal of Comparative Physiology 77, 65-79.

Heinrich, B. (1974) Thermoregulation in endothermic insects. Science 185, 747-756.

Heinrich, B. (1975) Thermoregulation in bumblebees. II. Energetics of warm-up and free flight. Journal of Comparative Physiology 166, 155-166.

Heinrich, B. (1979) Bumblebee Economics. Harvard University Press, Cambridge, MA.

Heinrich, B. (1984) Strategies of thermoregulation and foraging in two vespid wasps, Dolichovespula maculata and Vespula vulgaris. Journal of Comparative Physiology B 154, 175-180.

Heinrich, B. (1989) Beating the heat in obligate insect endotherms: the environmental problem and the organismal solutions. American Zoologist 29, 1157-1168.

Heinrich, B. (1993) The Hot Blooded Insects. Harvard University Press, Cambridge, MA.

Heinrich, B. \& Buchmann, S.L. (1986) Thermoregulatory physiology of the carpenter bee, Xylocopa varipuncta. Journal of Comparative Physiology B 156, 557-562.

Heinrich, B. \& Heinrich, M.J.E. (1983a) Size and caste in temperature regulation by bumblebees. Physiological Zoology 56, 552-562.

Heinrich, B. \& Heinrich, M.J.E. (1983b) Heterothermia in foraging workers and drones of the bumblebee Bombus terricola. Physiological Zoology 56, 563-567.

Heinrich, B. \& Mommsen, T.P. (1985) Flight of winter moths near $0^{\circ} \mathrm{C}$. Science 228, 177-179.

Helmuth, B.S.T. (1998) Intertidal mussel microclimates: predicting the body temperature of a sessile invertebrate. Ecological Monographs 68, 51-74.

Huey, R.B. (1987) Phylogeny, history, and the comparative method. New Directions in Ecological Physiology (eds M. E. Feder, A. F. Bennett, W. W. Burggren \& R. B. Huey), pp. 76-101. Cambridge University Press, Cambridge.

Kingsolver, J.G. (1979) Thermal and hydric aspects of environmental heterogeneity in the pitcher plant mosquito. Ecological Monographs 49, 357-376.

Kingsolver, J.G. (1983) Thermoregulation and flight in Colias butterflies: elevational patterns and mechanistic limitations. Ecology 64, 334-345.

Krogh, A. \& Zeuthen, E. (1941) The mechanism of flight preparation in some insects. Journal of Experimental Biology 18, 1-10.

Lloyd, A.H., Armbruster, W.S. \& Edwards, M.E. (1994) Ecology of a steppe-tundra gradient in interior Alaska. Journal of Vegetation Science 5, 897-912.

Maddison, W.P. \& Maddison, D.R. (1992) Macclade, Version 3. Sinauer, Sunderland, MA.

May, M.L. (1976) Warming rates as a function of body size in periodic endotherms. Journal of Comparative Physiology B 111, 55-70.

May, M.L. \& Casey, T.M. (1983) Thermoregulation and heat exchange in euglossine bees. Physiological Zoology 56, 541-551.

McGuire, A.D. (1993) Interactions for pollination between two synchronously blooming Hedysarum species (Fabaceae) in Alaska. American Journal of Botany 80, 147-152.

(C) 1999 British Ecological Society, Functional Ecology, 13, 711-724
McGuire, A.D. \& Armbruster, W.S. (1991) An experimental test for reproductive interactions between two sequentially blooming Saxifraga species (Saxifragaceae). American Journal of Botany 78, 214-219.

Michener, C.D. (1974) The Social Behavior of Bees. Harvard University Press, Cambridge, MA.

Michener, C.D., McGinley, R.J. \& Danforth, B.N. (1994) The Bee Genera of North and Central America. Smithsonian Institution Press, Washington.

Neter. J., Wasserman, W. \& Kutner, M.H. (1985) Applied Linear Statistical Models. D. D. Irwin, Inc., Homewood, IL.

Nicolson, S.W. \& Louw, G.N. (1982) Simultaneous measurement of evaporative water loss, oxygen consumption, and thoracic temperature during flight in a carpenter bee. Journal of Experimental Zoology 222, 287-296.

O’Neill, K.M. \& Kemp, W.P. (1992) Behavioral thermoregulation in two species of robber flies occupying different grassland microhabitats. Journal of Thermal Biology 17, 323-331.

O'Toole, C. \& Raw, A. (1991) Bees of the World. Facts On File, Oxford, UK.

Pagel, M.D. (1992) A method for the analysis of comparative data. Journal of Theoretical Biology 156, 431-442.

Pagel, M.D. \& Harvey, P.H. (1988) Recent developments in the analysis of comparative data. Quarterly Review of Biology 63, 413-440.

Parker, M.A. (1982) Thermoregulation by diurnal movement in the barberpole grasshopper (Dactylotum bicolor). American Midland Naturalist 107, 228-237.

Porter, W.P., Mitchell, J.W., Beckman, W.A. \& DeWitt, C.B. (1973) Behavioral implications of mechanistic ecology: thermal and behavioral modeling of desert endotherms and their microenvironment. Oecologia 13, $1-54$.

Porter, W.P., Munger, J.C., Stewart, W.E., Budaraju, S. \& Jaeger, J. (1994) Endotherm energetics: from a scalable individual-based model to ecological applications. Australian Journal of Zoology 42, 125-162.

Purvis, A. \& Rambaut, A. (1995) Comparative analysis by independent contrasts (CAIC). An Apple Macintosh application for analyzing comparative data. Computer Applications in Biological Sciences 11, 247-251.

Roig-Aisina, A. \& Michener, C.D. (1993) Studies of the phylogeny and classification of long-tongued bees. University of Kansas Science Bulletin 55, 123-162.

Roubik, D.W. (1989). Ecology and Natural History of Tropical Bees. Cambridge University Press, Cambridge, UK.

Rutowski, R.L., Demlong, M.J. \& Leffingwell, T. (1994) Behavioral thermoregulation at mate encounter sites by male butterflies (Asterocampa leilia, Nymphalidae). Animal Behaviour 48, 833-841.

Schultz, T.D. (1998) The utilization of patchy thermal microhabitats by the ectothermic insect predator, Cicindela sexguttata. Ecological Entomology 23, 444-450.

Sotavalta, O. (1954). On the thoracic temperature of insects in flight. Annals of the Zoological Society 'Vanamo' 16, $1-21$.

Stone, G.N. (1993a) Endothermy in the solitary bee Anthophora plumipes: Independent measures of thermoregulatory ability, costs of warm-up and the role of body size. Journal of Experimental Biology 174, 299-320.

Stone, G.N. (1993b) Thermoregulation in four species of tropical solitary bees: the roles of size, sex, and altitude. Journal of Comparative Physiology B 163, 317-326.

Stone, G.N. \& Willmer, P.G. (1989a) Endothermy and temperature regulation in bees: a critique of 'grab and stab' measurement of body temperature. Journal of Experimental Biology 143, 211-223. 
724

J. A. Bishop \& W. S. Armbruster
Stone, G.N. \& Willmer, P.G. (1989b) Warm-up rates and body temperatures in bees: the importance of body size, thermal regime and phylogeny. Journal of Experimental Biology 147, 303-328.

Underwood, B.A. (1991) Thermoregulation and energetic decision-making by the honeybees Apis cerana, Apis dorsata and Apis laboriosa. Journal of Experimental Biology 157, 19-34.

Waddington, K.D. (1990) Foraging profits and thoracic temperatures of honey bees (Apis mellifera). Journal of Comparative Physiology B 160, 325-329.
Ward, D. \& Seely, M.K. (1996) Behavioral thermoregulation of six Namib Desert tenebrionid beetle species (Coleoptera). Annals of the Entomological Society of America 89, 442-451.

Wathen, P., Mitchell, J.W. \& Porter, W.P. (1971) Theoretical and experimental studies of energy exchange from jackrabbit ears and cylindrically shaped appendages. Biophysical Journal 11, 1030-1047.

Received 25 March 1998; revised 6 January 1999; accepted 15 January 1999 